doi:10.5937/jaes9-1202

Paper number: 9(2011)4, 210, 456 - 464

\title{
COMBINATION FREE REPLACEMENT AND PRO-RATA WARRANTY POLICY OPTIMIZATION MODEL
}

\author{
MSc Dragan Stamenković \\ University of Belgrade, Faculty of Mechanical Engineering, Belgrade, Serbia \\ Dr Vladimir Popović \\ University of Belgrade, Faculty of Mechanical Engineering, Belgrade, Serbia \\ Dr Vesna Spasojević-Brkić \\ University of Belgrade, Faculty of Mechanical Engineering, Belgrade, Serbia \\ MSc Jovan Radivojević \\ University of Belgrade, Faculty of Mechanical Engineering, Belgrade, Serbia
}

Product development risk increases more and more every day. One of the factors that affect this risk is product warranty. Warranty is a powerful marketing instrument for the manufacturer and a good protection for both the manufacturer and the customer, but it always involves additional costs to the manufacturer. These costs depend on the product reliability and the warranty parameters. This paper deals with the optimization of these parameters for known product failure distribution to reduce the warranty costs to the manufacturer while retaining the promotional function of the warranty. Combination free replacement and pro-rata warranty policy is chosen as a model and the length of free replacement and pro-rata policy periods are varied, as well as the coefficients that define the pro-rata cost function. Warranty costs are obtained by using analytical equations and by simulation. The obtained results are shown and discussed and some concluding remarks are given.

Key words: free replacement warranty, pro-rata warranty, combination, costs, optimization

\section{INTRODUCTION}

More and more increasing product development risk is affected by the competition, schedule pressure, short deadlines, failure costs, rapid development of new materials, methods and complex systems, need for product cost reduction and safety issues [11]. Figure 1 shows the effects on an overall risk perception [09]. These effects are: customer requirements, safety, development risks, market pressure, legal and statutory regulations, management emphasis, warranty and service costs, competition, public liability and many more. Successful control of these risk factors is the main goal of reliability engineering development [10]. The focus of this paper is on the reduction of the effects warranty has on the product risk by choosing the best warranty policy.

Product unavailability depends on its reliability,

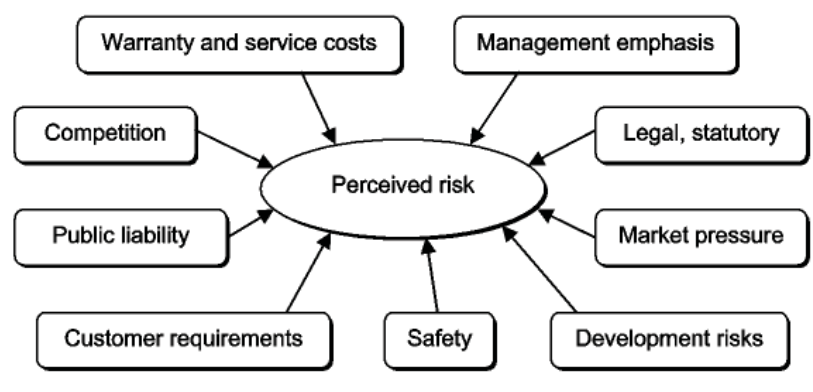

Figure 1. Risk perception [2]

maintainability and logistic support [06,12]. Product may become unavailable due to a hardware or software failure, human error or preventive maintenance (which requires the product to be excluded from service). When product or service becomes unavailable, a number of consequential costs can arise. These costs are called unavailability costs and may include [11]:

- warranty costs;

- liability costs; 
- costs caused by the decrease of the production function output;

- costs of providing the alternative services.

Unavailability costs should be identified by using the risk analysis techniques to determine the costs caused by the negative publicity which could eventually lead to customer loss. Costs of recovery from the negative effects that such publicity has on the company image, reputation and respectability and costs of reducing these risks are also unavailability costs. In many cases these costs are hard to asses, but it is sometimes possible to quantify them. For example, they can be assessed as a public campaign and marketing costs, or costs of compensation in order to keep the customers. These costs should be calculated whenever possible.

One of the key factors in the customer's decision-making process is product warranty. When choosing between several products with similar characteristics, customer will usually buy the product that provides a better warranty. A warranty is a contract or an agreement between the manufacturer and the customer. Under this agreement the manufacturer is obligated to repair, replace or provide service when the product fails to perform its function before the end of the warranty period. From the customer's point of view warranty has two functions - protective and informative. Warranty performs its protective function by assuring the customer that faulty products will either be repaired or replaced at no cost or at a reduced cost. Informative function of warranty means that it indirectly gives the customer the information about the product quality. From the manufacturer's point of view warranty also has two functions - protective and promotional. Protective function is reflected in warranty terms that specify the use of the product and limited coverage or no coverage at all in the case of misuse of the product. Promotional function from the manufacturer's point of view is associated with the informative function from the customer's point of view. As said before, when choosing between similar products, customer tends to buy the product with better warranty. This led to the competition between the manufacturers in offering the better warranty to attract more customers.

Warranty costs are usually borne by the manufacturer, depending on the reliability characteristics, maintainability and the performance of the product logistic support. The manufacturer could take important measures to control these characteristics during the design, development and manufacturing process and lower the warranty costs.

Warranties are defined by their terms and are usually time limited. Rarely they include consumer protection against unavailability costs due to the product unavailability. Warranties could be supplemented or replaced by a service agreement according to which the manufacturer performs complete preventive and corrective maintenance during the specific period of time, which could be extended to a limited period, or even to the end of the product life-cycle. There are three commonly used types of warranty policies [03,04]:

Free replacement warranty (FRW) - under this warranty, if a product fails before the end of the warranty period, the manufacturer is required to either repair the product or provide a new product at no cost to the customer. This type of policy is usually offered for repairable products. There are two types of free replacement warranty policy:

a) ordinary free replacement warranty - under this warranty, the repaired product is covered by the same type of warranty policy as it was before the failure. Warranty length for the repaired product is equal to the remaining length of the original warranty. This type of warranty is usually used for products such as home appliances, computers and vehicles;

b) unlimited free replacement warranty - under this warranty, the repaired product is covered by a new unlimited free replacement warranty. The length of the new warranty is equal to the original warranty length. This type of warranty policy is used for small electronic appliances with high early failure rates. The length of the unlimited free replacement warranty is usually short;

Pro-rata warranty (PRW) - under this warranty, if a product fails before the end of the warranty period, the manufacturer is required to replace the product at a cost, which is called pro-rata cost, that depends on the age of the product at the time of failure, and can be either a linear or non linear function of the remaining time in the warranty length. The replacement product is then covered by an identical new warranty. This type of warranty is usually offered with non-repairable products such as tyres, bulbs and batteries; 
Combination free replacement and pro rata warranty (FRW/PRW) - this type of policy is often used as a compromise, since the FRW policy is the most favourable to the customer and the PRW policy is the most favourable to the manufacturer. This type of warranty is comprised of two periods - a period of free replacement followed by a period of pro rata policy. Such combination has a significant promotional value to the manufacturer and at the same time provides adequate cost control for both manufacturer and customer in most cases [02,07]. Like the pro-rata warranty policy, combination warranty policy is usually offered with non repairable products.

A more comprehensive study on the types of warranty policies can be found in $[03,04]$. Warranty cost calculation is covered in $[01,08,13]$. In this paper a fully renewing combination free replacement and pro-rata policy will be considered with the objective to find the optimal warranty parameters. The optimal warranty parameters are those which lower the warranty costs, but still attract the customers. Parameters considered for optimization are: total warranty length, free replacement period length and two coefficients that define the pro-rata cost function, which will be defined later in the text.

\section{WARRANTY MODEL}

Fully renewing combination free replacement and pro-rata policy specifies two warranty periods, denoted w' and w. The manufacturer agrees to replace the product with a new product at no cost to the customer if it fails before w' $\left(w^{\prime}<w\right)$ expires. If a failure occurs in the time interval from $w$ ' to $w$ the product is replaced by the manufacturer at a fraction of the replacement cost (pro-rata cost) to the customer.

Warranty analysis in this paper is done for one type of passenger car batteries. This type of batteries has been on the market for 16 years and the manufacturer wanted to launch the new warranty policy along with the start of a new marketing campaign. According to the collected data from a 16 year long exploitation it is determined that life of this type of battery follows Weibull distribution with a shape parameter $\beta=1.63$ and a scale parameter $\eta=4380$ days. The price per battery unit excluding the warranty cost is $c^{\prime}=$ $82 €$. It is assumed that every failure results in a warranty claim, all warranty claims are valid and all failures are statistically independent.
In this warranty model the pro-rata cost is a linear function of time. Replacement cost to the manufacturer is calculated by the following equation $[02,07]$ :

$$
C(t)= \begin{cases}c, & 0 \leq t<w^{\prime}, \\ k c\left(1-\delta \frac{t-w^{\prime}}{w-w^{\prime}}\right), & w^{\prime} \leq t<w, \\ 0, & t \geq w .\end{cases}
$$

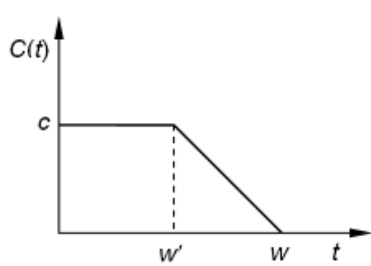

(a) $\delta=1, k=1$

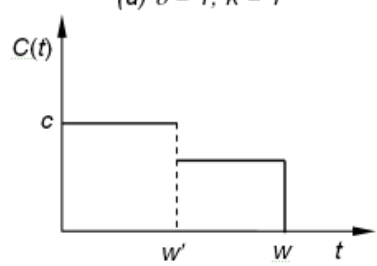

(c) $\delta=0,0<k \leq 1$

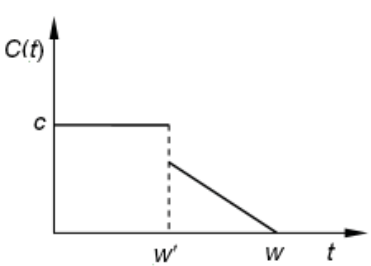

(b) $\delta=1,0<k \leq 1$

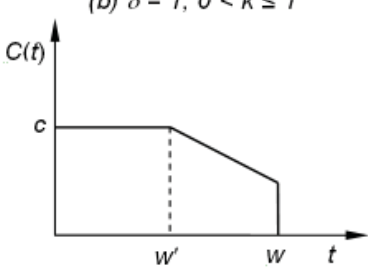

(d) $0<\delta \leq 1, k=1$
Figure 2. FRW/PRW policies with different values of proportionality coefficients

For $w^{\prime}=0$ FRW/PRW policy becomes PRW policy, and for $w^{\prime}=w$ FRW/PRW policy becomes FRW policy. Figure 2 illustrates how different values of proportionality coefficients k and $\delta$ affect the FRW/PRW policy.

Probability density function for a Weibull distribution is given by:

$$
f(t)=\frac{\beta}{\eta}\left(\frac{t}{\eta}\right)^{\beta-1} e^{-\left(\frac{t}{\eta}\right)^{\beta}}
$$

and the cumulative distribution function is:

$$
F(t)=1-e^{-\left(\frac{t}{\eta}\right)^{\beta}}
$$

The number of failures for one battery unit by time $t$ has a geometric distribution, so the expected number of failures for one battery unit by time $t$ is:

$$
E[N(t)]=\frac{F(t)}{1-F(t)}
$$

The expected number of failures for the whole lot by time $t$ can be calculated by multiplying the 
expected number of failures for one battery by the product lot size:

$$
L \cdot E[N(t)]=L \cdot \frac{F(t)}{1-F(t)}
$$

The total number of failures for the whole lot in the interval from $t$ to $t+d t$ is:

$L \cdot d E[N(t)]=L \cdot \frac{f(t)}{(1-F(t))^{2}}$

and the expected total cost to the manufacturer for the failures from $t$ to $t+d t$ is:

$d\left(T_{C}\right)=C(t) \cdot L \cdot \frac{f(t)}{(1-F(t))^{2}}$

where $C(t)$ is the replacement cost to the manufacturer at time t. Total expected cost to the manufacturer for the whole warranty period is then calculated by the following equation:

$$
\begin{aligned}
T_{C}= & L \cdot\left(\int_{0}^{w^{\prime}} c \cdot \frac{f(t)}{(1-F(t))^{2}} d t+\right. \\
& \left.+\int_{w^{\prime}}^{w} k c\left(1-\delta \frac{t-w^{\prime}}{w-w^{\prime}}\right) \cdot \frac{f(t)}{(1-F(t))^{2}} d t\right)
\end{aligned}
$$

Warranty cost to the manufacturer per unit is obtained by dividing the total cost with the lot size L:

$$
\begin{aligned}
r= & \frac{T_{C}}{L}=\int_{0}^{w^{\prime}} c \cdot \frac{f(t)}{(1-F(t))^{2}} d t+ \\
& +\int_{w^{\prime}}^{w} k c\left(1-\delta \frac{t-w^{\prime}}{w-w^{\prime}}\right) \cdot \frac{f(t)}{(1-F(t))^{2}} d t
\end{aligned}
$$

For the purpose of this paper, analytical equations (8) and (9) are solved numerically using MATLAB. Warranty cost can also be obtained by performing the simulation in order to compare the simulated results with those obtained using the analytical equations. The life-cycle of every battery unit in a lot is simulated using MATLAB. Lot size for the simulation is set to 10000 units. If one battery unit fails, simulation of life-cycle of the replacement battery starts from the beginning. This process is repeated until one of the replacement batteries reaches full warranty period without a failure for every battery in the lot. Total expected cost to the manufacturer then can be calculated using the equation:

$$
\begin{aligned}
T_{C} & =\sum_{l=1}^{N} C\left(t_{l}\right)=\sum_{m=1}^{N_{1}} c+\sum_{n=1}^{N_{2}} k c\left(1-\delta \frac{t_{n}-w^{\prime}}{w-w^{\prime}}\right)= \\
& =\left(c^{\prime}+r\right)\left(N_{1}+k \sum_{n=1}^{N_{2}}\left(1-\delta \frac{t_{n}-w^{\prime}}{w-w^{\prime}}\right)\right),
\end{aligned}
$$

where $\mathrm{N} 1$ and $\mathrm{N} 2$ are the numbers of failures in the free replacement period and pro-rata warranty period, respectively. After dividing the both sides by the lot size $L$ equation (10) becomes:

$$
r=\frac{T_{C}}{L}=\frac{\left(c^{\prime}+r\right)}{L}\left(N_{1}+k \sum_{n=1}^{N_{2}}\left(1-\delta \frac{t_{n}-w^{\prime}}{w-w^{\prime}}\right)\right)
$$

The warranty cost to the manufacturer per unit then can be calculated as:

$$
r=\frac{\frac{c^{\prime}}{L}\left(N_{1}+k \sum_{n=1}^{N_{2}}\left(1-\delta \frac{t_{n}-w^{\prime}}{w-w^{\prime}}\right)\right)}{\left(1-\frac{1}{L}\left(N_{1}+k \sum_{n=1}^{N_{2}}\left(1-\delta \frac{t_{n}-w^{\prime}}{w-w^{\prime}}\right)\right)\right)}
$$

Warranty costs are calculated and simulated for the warranty period length $\mathrm{w}$ ranging from 1 to 6 years and the free replacement period length $w$ ' ranging from 0 to $w$ for three different polices: the first policy with proportionality coefficients $\mathrm{k}=1$ and $\delta=1$, the second with $\mathrm{k}=0.5$ and ,$\delta=1$ and finally, the third with $\mathrm{k}=1$ and $\delta=$ 0.5 .

\section{DISCUSSION OF RESULTS}

Tables 1 to 3 show unit prices after adding the warranty cost for different warranty and free replacement period length for all three policies considered. In these tables cs and ca denote the price values obtained by simulation and by using analytical equations, respectively. For equal values of $w$ an w' FRW/PRW becomes FRW policy, so the analytical price values for these cases are identical for all three policies. Because of this, unit price curves start at the same points on all three diagrams. Displayed results also show that simulated price values follow analytical ones closely.

Figures 3 to 5 show the analytical unit price values after adding the warranty cost as a function of warranty period length $w$ and free replacement period length w' for all three policies. These diagrams show the effects that change of the proportionality coefficients k and $\delta$ and free replace- 
ment period length w' has on the unit price-warranty length relation. By reducing the proportionality coefficient $\mathrm{k}$ price curve slope decreases, while reduction of proportionality coefficient $\delta$ has the opposite effect.

Table 1. Simulated and analytical unit price values after adding the warranty cost for $k=1$ and $\delta=1$

\begin{tabular}{|c|c|c|c|c|c|c|c|c|c|c|c|c|c|c|}
\hline \multirow{3}{*}{ w } & \multicolumn{14}{|c|}{$w^{\prime}$} \\
\hline & \multicolumn{2}{|c|}{0} & \multicolumn{2}{|c|}{1} & \multicolumn{2}{|c|}{2} & \multicolumn{2}{|c|}{3} & \multicolumn{2}{|c|}{4} & \multicolumn{2}{|c|}{5} & \multicolumn{2}{|c|}{6} \\
\hline & Cs & $\mathrm{Ca}$ & Cs & $\mathrm{Ca}$ & Cs & $\mathrm{Ca}$ & Cs & $\mathrm{Ca}$ & Cs & $\mathrm{Ca}$ & Cs & $\mathrm{Ca}$ & Cs & $\mathrm{Ca}$ \\
\hline 1 & 82.57 & 82.55 & 83.26 & 83.47 & & & & & & & & & & \\
\hline 2 & 83.66 & 83.74 & 85.13 & 84.98 & 86.98 & 86.81 & & & & & & & & \\
\hline 3 & 85.53 & 85.51 & 87.14 & 87.06 & 89.41 & 89.26 & 91.94 & 92.14 & & & & & & \\
\hline 4 & 88.52 & 87.87 & 90.44 & 89.80 & 93.58 & 92.43 & 95.82 & 95.83 & 100.69 & 100.19 & & & & \\
\hline 5 & 92.05 & 90.95 & 94.55 & 93.33 & 98.65 & 96.49 & 102.38 & 100.56 & 106.55 & 105.78 & 112.54 & 112.53 & & \\
\hline 6 & 96.99 & 94.92 & 99.37 & 97.85 & 104.33 & 101.71 & 110.11 & 106.66 & 116.79 & 113.05 & 123.92 & 121.39 & 131.73 & 132.55 \\
\hline
\end{tabular}

Table 2. Simulated and analytical unit price values after adding the warranty cost for $k=0.5$ and $\delta=1$

\begin{tabular}{|c|c|c|c|c|c|c|c|c|c|c|c|c|c|c|}
\hline \multirow{3}{*}{ W } & \multicolumn{14}{|c|}{$w^{\prime}$} \\
\hline & \multicolumn{2}{|c|}{0} & \multicolumn{2}{|c|}{1} & \multicolumn{2}{|c|}{2} & \multicolumn{2}{|c|}{3} & \multicolumn{2}{|c|}{4} & \multicolumn{2}{|c|}{5} & \multicolumn{2}{|c|}{6} \\
\hline & Cs & $\mathrm{Ca}$ & Cs & $\mathrm{Ca}$ & Cs & $\mathrm{Ca}$ & Cs & $\mathrm{Ca}$ & Cs & $\mathrm{Ca}$ & Cs & $\mathrm{Ca}$ & Cs & $\mathrm{Ca}$ \\
\hline 1 & 82.32 & 82.27 & 83.45 & 83.47 & & & & & & & & & & \\
\hline 2 & 82.95 & 83.47 & 84.20 & 84.21 & 87.19 & 86.81 & & & & & & & & \\
\hline 3 & 83.59 & 83.72 & 85.65 & 85.23 & 88.38 & 88.02 & 92.22 & 92.14 & & & & & & \\
\hline 4 & 85.01 & 84.83 & 86.87 & 86.52 & 90.45 & 89.53 & 94.38 & 93.95 & 100.43 & 100.19 & & & & \\
\hline 5 & 86.68 & 86.24 & 89.17 & 88.12 & 92.46 & 91.39 & 97.84 & 96.17 & 105.54 & 102.91 & 111.75 & 112.53 & & \\
\hline 6 & 88.87 & 87.99 & 91.41 & 90.09 & 95.89 & 93.67 & 102.74 & 98.87 & 111.37 & 106.23 & 120.42 & 116.79 & 133.12 & 132.55 \\
\hline
\end{tabular}


Table 3. Simulated and analytical unit price values after adding the warranty cost for $k=1$ and $\delta=0.5$

\begin{tabular}{|c|c|c|c|c|c|c|c|c|c|c|c|c|c|c|}
\hline \multirow{3}{*}{ w } & \multicolumn{14}{|c|}{$w^{\prime}$} \\
\hline & \multicolumn{2}{|c|}{0} & \multicolumn{2}{|c|}{1} & \multicolumn{2}{|c|}{2} & \multicolumn{2}{|c|}{3} & \multicolumn{2}{|c|}{4} & \multicolumn{2}{|c|}{5} & \multicolumn{2}{|c|}{6} \\
\hline & Cs & $\mathrm{Ca}$ & Cs & $\mathrm{Ca}$ & Cs & $\mathrm{Ca}$ & Cs & $\mathrm{Ca}$ & Cs & $\mathrm{Ca}$ & Cs & $\mathrm{Ca}$ & Cs & $\mathrm{Ca}$ \\
\hline 1 & 83.07 & 83.00 & 83.46 & 83.47 & & & & & & & & & & \\
\hline 2 & 85.04 & 85.25 & 85.48 & 85.88 & 86.97 & 86.89 & & & & & & & & \\
\hline 3 & 89.03 & 88.70 & 88.94 & 89.53 & 91.02 & 90.68 & 92.45 & 92.14 & & & & & & \\
\hline 4 & 94.37 & 93.63 & 95.37 & 94.71 & 95.67 & 96.15 & 98.09 & 97.96 & 99.25 & 100.19 & & & & \\
\hline 5 & 100.78 & 100.60 & 103.25 & 102.03 & 103.65 & 103.89 & 107.13 & 106.21 & 109.03 & 109.05 & 112.64 & 112.53 & & \\
\hline 6 & 111.73 & 110.62 & 114.30 & 112.59 & 116.58 & 115.10 & 117.83 & 118.21 & 124.51 & 122.03 & 127.88 & 126.73 & 131.56 & 132.55 \\
\hline
\end{tabular}

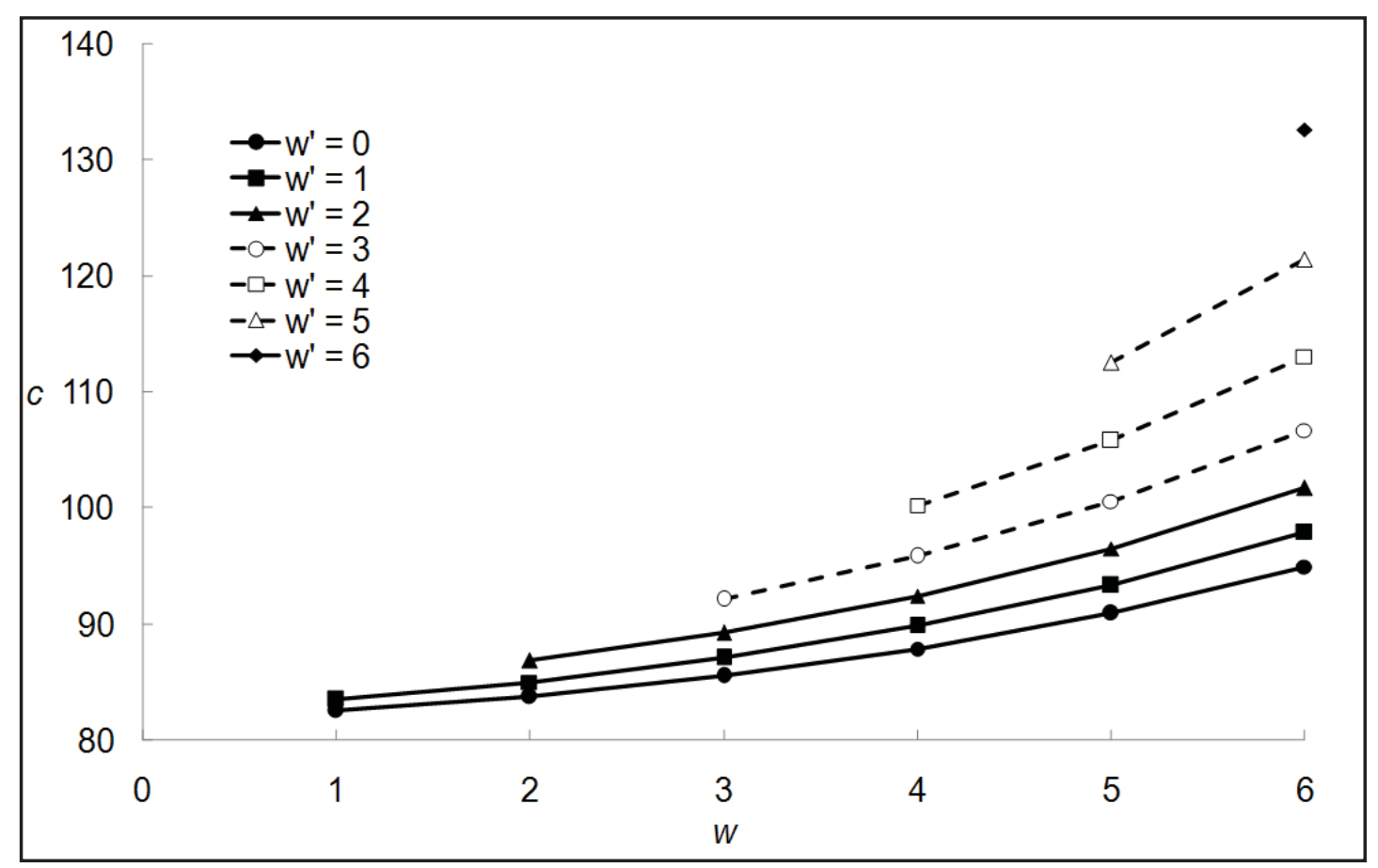

Figure 3. Analytical unit price values after adding the warranty cost for $k=1$ and $\delta=1$

Beside the costs to the manufacturer, the promotional effect needs to be considered for every warranty policy variant. For example, for the warranty policy defined by $\mathrm{k}=0.5$ and $\delta=1$ (Figure 4), analytical unit price value after adding the warranty cost for $w^{\prime}=5$ and $w^{\prime}=0$ (ca $=$ 86.245 ) is less than the price value for $w=2$ and $w^{\prime}=2(c a=86.808)$. Although longer, and thus potentially having greater promotional value, the first of two variants is characterised by less cost to the manufacturer. The analysis of promotional value of warranty policies is not the subject of this paper and should by acquired through market research. 


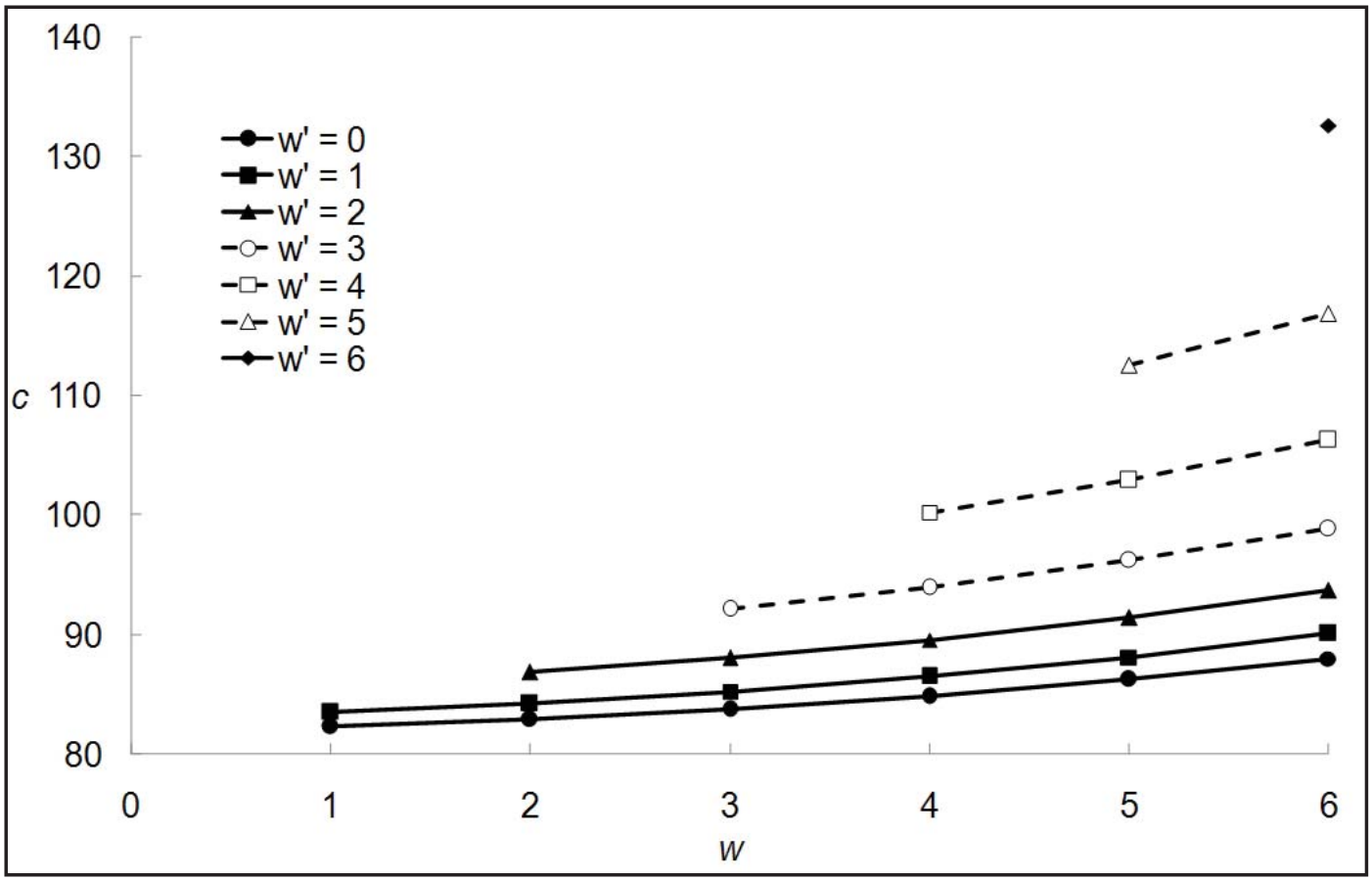

Figure 4. Analytical unit price values after adding the warranty cost for $\mathrm{k}=0.5$ and $\delta=1$

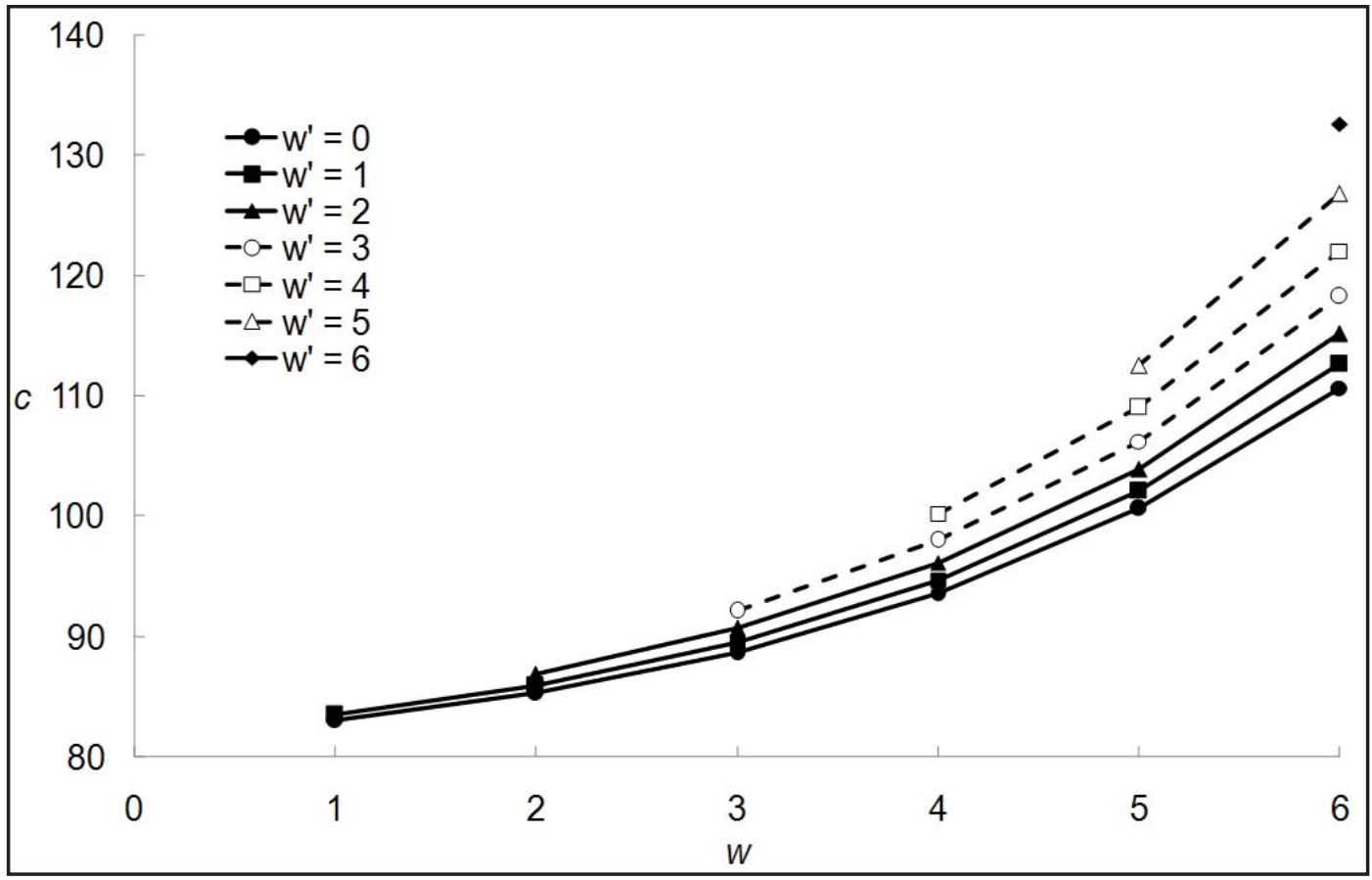

Figure 5. Analytical unit price values after adding the warranty cost for $\mathrm{k}=1$ and $\delta=0.5$

\section{CONCLUSION}

Product warranty is one of the key factors that affect the risk involved with product development. By choosing the best warranty policy manufacturer can reduce this risk. The best policy is one having the best ratio of warranty cost to the manufacturer to promotional value to the buyer. In the present paper the effects that change of parameters k and $\delta$ that define warranty has on its cost to the manufacturer was considered. It was done by both calculating and simulating the warranty costs for three different FRW/PRW policy variants and different length of warranty period and free replacement period. It is also important to notice that conducted simulation proved 
useful in the determination of warranty costs. Shown results define the relation between the proportionality coefficients k and $\delta$ and warranty cost to the manufacturer that is depicted through the change of unit price after adding the warranty cost. These results, after conducting the market research and obtaining the promotional value for all of three warranty variants, enable the manufacturer to conduct cost-benefit analysis and choose the best warranty policy.

\section{ACKNOWLEDGEMENTS}

This paper is a part of two important projects of The Ministry of Science and Technological Development of Serbia (project number TR 35045 - "Scientific-Technological Support to Enhancing the Safety of Special Road and Rail Vehicles" and TR 35040 - "Developed New Methods for Diagnosis and Examination Mechanical Structures"). The authors wish to express their gratitude to the investors in these projects, and to all persons who helped making this paper better.

\section{NOTATIONS}

$\beta$ - Weibull distribution shape parameter

$\eta$ - Weibull distribution scale parameter

c' - battery unit price before adding the warranty cost

$r$ - expected warranty cost per battery unit

$c$ - unit price after adding the warranty cost,

$c=c^{\prime}+r$

$\mathrm{k}$ - proportionality coefficient of $\mathrm{c}$

$\delta$ - proportionality coefficient of time of failure in the warranty interval

$\mathrm{N}_{(\mathrm{t})}$ - number of failures at time $\mathrm{t}$

$L$ - battery lot size for warranty cost determination

w - warranty period length

w' - free replacement period length

$\mathrm{C}_{(t)}$ - replacement cost to the manufacturer at time $\mathrm{t}$

$\mathrm{T}_{\mathrm{C}}$ - total warranty cost of a lot of size $\mathrm{L}$.

Most of the notations are taken from [5].

\section{REFERENCES}

1) Balcer, Y., Sahin, I., (1986) Replacement Costs Under Warranty: Cost Moments and Time Variability, Operations Research, 34(4), 554-559.
2) Blischke, W.R., Murthy, D.N.P., (1996) Product Warranty Handbook, New York: Marcel Dekker.

3) Blischke, W.R., Rezaul, M.K., Murthy, D.N.P., (2011) Warranty Data Collection and Analysis, London: Springer Verlag.

4) Guangbin, Y., (2007) Life Cycle Reliability Engineering, Hoboken: John Wiley \& Sons.

5) http://www.weibull.com/hotwire/issue100/ relbasics100.htm, consulted 7 September 2011.

6) Mitic, S., Rakicevic, B., Stamenkovic, D., Popovic, V., (2011) Advanced Theoretical-Experimental Method for Optimization of Dynamic Behaviour of Firefighting Vehicle Modular Superstructure, Journal of Applied Engineering Science, 9(1), 267-275.

7) Mitra, A., Patankar, J.G., (1997) Market Share and Warranty Costs for Renewable Warranty Programs, International Journal of Production Economics, 50(2-3), 155-168.

8) Nguyen, D.G., Murthy, D.N.P., (1984) Cost Analysis of Warranty Policies, Naval Research Logistics Quarterly, 31(4), 525-541.

9) O'Connor, P., (2002) Practical Reliability Engineering (4th edn), Hoboken: John Wiley \& Sons.

10) Popovic, V., Vasic, B., (2008) Review of Hazard Analysis Methods and Their Basic Characteristics, FME Transactions, 36(4), 181-187.

11) Popovic, V., Vasic, B., Petrovic, V., (2010) The Possibility for FMEA Method Improvement and Its Implementation into Bus Life Cycle, Strojniski vestnik - Journal of Mechanical Engineering, 56(3), 179-185.

12) Popovic, V., Vasic, B., Rakicevic, B., Vorotovic, G., (in press) Optimization of Maintenance Concept Choice Using Risk Decision Factor - a Case Study, International Journal of Systems Science (Accepted for publication April 2011, doi: 10.1080/00207721.2011 .563868).

13) Ritchken, P.H., (1985) Warranty Policies for Non-Repairable Items under Risk Aversion, IEEE Transactions on Reliability, 34(2), 147150.

Paper sent revision: 21.11.2011.

Paper ready for publication: 13.12.2011. 